\title{
ENDOSSO DE MARCA: COMPARAÇÃO DA INFLUÊNCIA DE BLOGUEIRAS E CELEBRIDADES NA ATITUDE EM RELAÇÃO À MARCA
}

Objetivo: Esta pesquisa tem por objetivo comparar a influência que celebridades tradicionais e blogueiras, como endorsers de marca, exercem na atitude em relação à marca, mensurando a credibilidade delas, na opinião do consumidor, como porta-vozes de uma marca.

Método: Experimento

Originalidade/Relevância: A literatura investigada não apresentava modelos causais comparando os efeitos de celebridades e blogueiras e havia visões conflitantes: de um lado, a visão de que blogueira e celebridade estariam em patamares distintos em seu poder e extensão de influência na atitude em relação à marca que anunciavam; por outro lado, a perspectiva de uma mudança nessa situação estaria em curso e que ambas poderiam se equiparar, uma vez que, além da credibilidade da fonte, o significado cultural construído é fator relevante no sucesso do endosso.

Resultados: Diferentemente do que havia sido sinalizado pela literatura anterior, mas em linha com as últimas evidências no mercado, os resultados mostraram que não há diferença significativa na atitude em relação à marca se o endosso da marca é feito por uma celebridade ou blogueira, sendo que estas também possuem níveis equivalentes de credibilidade junto ao público.

Contribuições teóricas: Este estudo contribui para o entendimento do papel das celebridades tradicionais e de um tipo de influente digital, a blogueira, e dos respectivos efeitos nos nas ações de endosso de marca, adicionando ao modelo teórico prevalente a perspectiva de que o significado cultural construído não pode ser ignorado na atribuição de credibilidade aos endorsers.

Palavras-chave: Endosso de Marca. Blogueira. Celebridade. Marca. Credibilidade.

\section{BRAND ENDORSEMENT: COMPARISON OF THE INFLUENCE OF BLOGGERS AND CELEBRITIES IN ATTITUDE REGARDING BRAND}

Objective: This study compares if celebrities and bloggers' influence is the same on the attitude towards the brand and measures which of them have higher credibility as endorser, based on the consumer's opinion.

Method: Experiment

Relevance/Originality: The literature review did not present causal models comparing the effects of celebrities and bloggers. Also, there were conflicting views: on the one hand, the view that blogger and celebrity would be at different levels regarding their power and extent of influence in the attitude towards the brand they endorse; on the other hand, the prospect of a change in this situation would be underway and that both could be equated, since, in addition to the credibility of the source, the cultural meaning is a relevant factor in the success of the endorsement tactic.

Main results: Unlike the previous literature, but in line with the latest evidence on the market, the results showed that there is no significant difference in attitude toward the brand if the brand endorsement is performed by a celebrity or blogger. Additionally, they present equivalent levels of credibility.

Contribuitions: This study contributes to the understanding of the role of traditional celebrities and a digital influencer type, the blogger, and their effects on brand endorsement tactics, adding to the prevailing theoretical model the perspective that the cultural meaning cannot be ignored in the attribution of credibility to endorsers.

Keywords: Brand Endorsement. Blogger. Celebrity. Brand. Credibility.

Bruna Santos Bravo ${ }^{1}$ Juliana Rossignoli Saueia ${ }^{2}$ Karin Ligia Brondino-Pompeo ${ }^{3}$

\footnotetext{
${ }^{1}$ Graduada em Administração de Empresas pela Escola Superior de Propaganda e Marketing - ESPM. São Paulo, Brasil. E-mail: brunasbravo@outlook.com

${ }^{2}$ Graduada em Administração de Empresas pela Escola Superior de Propaganda e Marketing - ESPM. São Paulo, Brasil. E-mail: julianasaueia@gmail.com

${ }^{3}$ Doutora em Administração de Empresas pela Escola de Administração de Empresas de São Paulo da Fundação Getulio Vargas - EAESP/FGV. Professora da Escola Superior de Propaganda e Marketing - ESPM. São Paulo, Brasil. E-mail: karin.brondino@me.com
} 


\section{INTRODUÇÃO}

A marca tem o poder de conferir um conjunto de atributos específicos para determinada empresa, intangíveis inclusive, permitindo tornar-se diferente dos demais competidores (Keller \& Lehmann, 2006). Assim, ao consumir o produto de uma marca, não se está adquirindo apenas o material, mas o imaterial e o simbólico (Taschner, 2010).

Uma das formas empregadas para a construção dos significados de uma marca é a associação secundária, prática na qual os gestores agregam sua marca a uma outra, buscando com isso a transferência de atributos entre elas (Keller, 2003). O endosso de uma marca por celebridades é uma tática de associação secundária frequente e poderosa (Byrne, Whitehead, \& Breen, 2003; Escalas \& Bettman, 2005; McCracken, 1989)

Celebridades são pessoas comumente reconhecidas pelo público, cujas aparições na mídia são constantes e que geram influência em um grupo significativo de pessoas. Essa influência torna o endosso de celebridade a uma marca uma ação frequente há anos (Freire, Behling, \& Reinert, 2010; Silva, Lopes, \& Silva, 2012). A literatura dedicada ao estudo dos impactos das celebridades nas marcas endossadas é vasta e, de forma geral, os resultados encontrados são positivos. Dal Bó, Milan e Toni (2012), por exemplo, notaram que significados atribuídos à celebridade usada na campanha de uma marca de sandálias fluíram para a marca, trazendo benefícios para a imagem de ambas e também retornos financeiros. Já Choi e Rifon (2012) sustentam que a avaliação dos anúncios e a intenção de compra dos produtos são mais elevadas se há congruência entre as características da celebridade endossante e as que os consumidores têm como ideais para si mesmos.

Com a massificação da internet e o surgimento dos espaços de interação entre os que produzem conteúdos e os que os lêem, o blogueiro foi um dos personagens que ganharam relevância (Kaplan \& Haenlein, 2010). Entre as muitas blogueiras existentes, há algumas que são extremamente influentes, tendo seu conteúdo lido e seguido por muitas pessoas. Camila Coutinho, por exemplo, autora do blog Garotas Estúpidas, foi escolhida em 2015 pela revista Forbes como um dos 30 jovens abaixo dos 30 anos que representa o futuro do País (Forbes Brasil, 2015) e possuía em 2017 1,8 milhões de seguidores no Instagram, 600 mil no Facebook e 269 mil inscritos em seu canal no YouTube (Garotas Estúpidas, 2017). O sucesso das blogueiras atraiu o interesse das empresas que, atualmente, além dos atores, cantores e esportistas, têm usado as blogueiras como endossantes das marcas (Teixeira, 2014). Mais relevante ainda, as blogueiras têm transposto a fronteira online $\mathrm{e}$ passado a figurar em campanhas offline, aparecendo, por exemplo, em anúncios de revistas das marcas endossadas (SMB, 2015), passando a ocupar um espaço usualmente dedicado às celebridades.

Entretanto, na análise de Primo (2009), raros seriam os exemplos de blogueiras que conseguiram um grande reconhecimento fora da blogsfera. Celebridades e blogueiras, portanto, não teriam o mesmo potencial de geração de benefícios para as marcas. Por outro lado, Keel e Nataraajan (2012) e Zanette (2015) cogitam que a diferença de status antes existente entre esses dois tipos de endossantes talvez não seja mais realidade. Modelos de causalidade que testem as semelhanças e as diferenças nos impactos desses dois perfis de endossantes - celebridades e blogueiras - não estavam disponíveis no momento deste estudo.

Dessa observação, resulta o questionamento: blogueiras e celebridades tradicionais se distinguem nos potenciais resultados para as marcas endossadas?

O objetivo principal desta pesquisa é comparar a influência de blogueiras e celebridades como endossantes na atitude em relação à marca. Mais especificamente, deseja-se determinar se há diferenças na credibilidade desses dois grupos celebridades e blogueiras - e mensurar a eficácia do endosso da marca quando realizado por uma blogueira e quando realizado por uma celebridade.

Com esta investigação, espera-se ter mais clareza dos efeitos gerados pela diversidade de endorsers, contribuindo assim para ampliar o conhecimento, tanto da comunidade acadêmica quanto dos gestores, a respeito dessa prática, dando a estes mais subsídio na decisão da escolha do endossante.

\section{REVISÃO DA LITERATURA}

Os consumidores são influenciados de diversas maneiras por outros indivíduos, por meio da propaganda boca-a-boca, por exemplo, que propaga inspirações dentro do público alvo, por meio de conselhos e informações fornecidas por outros consumidores, que podem ser também tidos como líderes de opinião. Os líderes de opinião são indivíduos que influenciam outros, fazendo-os, inclusive, mudar de opinião de modo a iniciarem um processo de aceitação de novos produtos e tendências (Watts \& Dodds, 2007). Muitas vezes, esses líderes de opinião são pessoas interessadas e que acompanham a moda e passam a dar conselhos, informações a respeito da tendência para outros consumidores (Goldsmith, 2000).

Neste estudo, dois líderes de opinião serão comparados: as celebridades, que já são tidas e conhecidas como líderes de opinião há mais tempo, 
e as blogueiras, que podem ser consideradas novas líderes de opinião.

\subsection{Celebridades}

O uso do termo "celebridade" começou no século XVI e é derivado do latim "celebritas" que quer dizer "afamado", "notável" (Primo, 2009). Na literatura de marketing, celebridades são indivíduos muito bem reconhecidos por terem uma atenção especial da mídia (Jin \& Phua, 2014). Freire, Behling e Reinert (2010) ainda acrescentam que a celebridade é vista como uma personalidade conhecida publicamente por inúmeras pessoas e que exercem profissões como modelos, atores, estrelas de televisão e atletas.

O reconhecimento dos veículos de mídia e do grande público pode ter razões distintas. O reconhecimento pode ser decorrente de linhagem ou hereditariedade, ou então pode ser fruto de realizações individuais em função de uma habilidade extraordinária, ou ainda atribuído por intermediários culturais, como a mídia de massa, que passa a dar atenção a determinadas pessoas não porque elas atingiram feitos incríveis, mas porque têm um comportamento bizarro, atípico ou inadequado que instiga a curiosidade das pessoas e ajuda a vender notícias com viés sensacionalista (Rojek, 2008).

Kate Middleton, por exemplo, é uma celebridade muito visada. Os veículos de comunicação cobrem extensivamente todos os eventos oficiais ou sociais dos quais ela participa. A duquesa de Cambridge, título de nobreza conquistado a partir do seu casamento com o princípio William do Reino Unido, possui duas das características exploradas acima: tem a atenção da mídia de massa porque conseguiu algo atípico - de plebeia se tornou princesa - e passou a fazer parte de uma linhagem. Sempre que aparece na mídia, o modelo idêntico ao que está vestindo vira sucesso de vendas nas lojas. Em função desse efeito, celebridades se aproveitam do reconhecimento público e podem usá-lo em seu favor, assim como em favor de marcas e produtos (Silva et al., 2012).

Ao tornar-se reconhecida pela mídia, a vida de uma celebridade passa a ser mais notada, "um objeto de interesse público" (Silva \& Baptista, 2013, 6), o que faz com que as pessoas busquem de alguma forma se parecer com elas, tentativa essa que pode vir em decorrência de sua forma de falar, agir, vestir e até das marcas que usam, sendo que a principal forma de aproximação com a celebridade é por meio do vestuário (Silva \& Baptista, 2013).

Independentemente da forma como a celebridade conseguiu sua fama, a maneira como ela é mencionada pela mídia influencia em seu posicionamento perante à sociedade, de maneira a influenciar seu relacionamento com os consumidores (Silva \& Baptista, 2013).

Além de inúmeros atributos como inteligência, beleza, carisma, sofisticação e glamour, as celebridades são reconhecidas e consideradas muitas vezes como alguém em quem se espelhar, por serem vistas como fórmulas de sucesso a serem copiadas (Freire, Behling, \& Reinert, 2010).

\subsubsection{O Endossodo de Celebridades}

Pela notável influência que a celebridade exerce nas pessoas, criando verdadeiros advogados defensores e seguidores de sua imagem e opinião, as empresas passaram a utilizá-las frequentemente em suas propagandas, sendo, inclusive, considerado um tipo de campanha segura (Freire, Behling, \& Reinert, 2010). Keel e Nataraajan (2012) afirmam que o objetivo desse uso é atrair atenção, percepção e virtude para a marca que esteja sendo vinculada à celebridade. Segundo Hung (2014), um dos motivos do sucesso desse tipo de endosso é o fato das celebridades já terem fãs leais e admiradores que confiam na figura que elas representam, passando essa relação de confiança e lealdade para a marca. A resposta à estratégia de endosso vem, dessa forma, por parte dos fãs da celebridade endossante, que já possuem um laço psicológico com a celebridade (Escalas \& Bettman, 2005).

O objetivo seria é ganhar consumidores e lealdade à marca no mercado atual, onde se tem fluxo muito rápido de informações, inclusive sobre produtos, pela internet, e ter um consumidor leal à sua marca nessas circunstâncias auxilia a manter um bom índice de vendas (Hung, 2014; Rojek, 2008).

Um modelo teórico comumente usado para avaliar o poder da celebridade como endossante é o modelo da credibilidade da fonte (Brockington, 2015; Hovland \& Weiss, 1951; Ohanian, 1991). Esse modelo sugere que a o mecanismo do endosso bemsucedido realizado pelas celebridades reside na credibilidade destas como porta-vozes da marca anunciada.

McCracken (1989) apresenta uma perspectiva que, ao contrário do modelo teórico prevalente que se fundamenta na credibilidade da fonte - ou seja, a credibilidade da celebridade seria a principal variável de influência nos resultados da ação da marca - considera o significado cultural das celebridades, construído junto ao público e em conjunto com o público ao curso da carreira. Ele defende que esse significado cultural é que é transferido para o produto. Assim, com o produto embebido do significado da celebridade, ele é transferido para o consumidor quando este o compra e o usa.

Portanto, o processo para a escolha da celebridade endossante depende do significado 
culturalmente criado e compartilhado que essa celebridade carrega consigo. $\mathrm{O}$ gestor deseja que esse significado seja passível de transferência para o produto, que passará, por fim, ao consumidor. Dessa forma, o poder de persuasão em um endosso por celebridade tem mais a ver com a celebridade em questão do que com o produto endossado. A credibilidade também é um aspecto importante, mas ela faz parte de um significado mais amplo (McCracken, 1989).

Assim, como existe essa transferência de significado no processo de endossar, deve-se ter bem claro quais valores se pretende passar para o produto endossado, e com esse diagnóstico, escolher uma celebridade capaz de passar esse valor. Portanto, os valores devem ser benéficos a ela e ao produto para que o endosso tenha uma boa eficácia (McCracken, 1989).

A mídia social vem sendo utilizada também como um instrumento para os consumidores comentarem sobre um produto, marca e/ou serviço, de forma a intensificar a propaganda boca-a-boca (Jin \& Phua, 2014). Nesse contexto, as celebridades têm um papel importante porque conseguem comunicar-se por meio das redes sociais ajudando na divulgação. Um exemplo é o caso de Sabrina Sato com a marca de absorvente Always. A promoção que a marca fez começou com um vídeo aparentemente íntimo de Sabrina veiculado pela internet. Em seguida, Sabrina fez uma postagem em seu Instagram sobre o absorvente, que teve suas vendas consideravelmente maiores depois da ação de endosso (Ego, 2015).

Outra forma que os internautas passaram a ter para partilhar suas opiniões e ideias sobre um dado assunto, além das redes sociais, foi através da participação ativa nos comentários dos blogs.

\subsection{Os Blogs e as Blogueiras}

$\mathrm{Na}$ época da globalização e do avanço tecnológico, a internet transformou-se em um espaço coletivo de interação, no qual a maneira de consumir, produzir e transferir informações é diferente (Aquino, 2009). No meio desse contexto, surgiu, por volta de 1997, o blog, que é uma abreviação de web (referente a uma página na internet) e log (que significa diário de navegação) (Schittine, 2004).

Esse sistema possibilitou que qualquer indivíduo publicasse o que desejasse em sua página da rede (Rocha, 2003). Tal publicação feita por blogueiros representa, em geral, características pessoais e sociais do autor. Quanto ao tema abordado, o blogueiro geralmente considera um conteúdo que ele se entusiasme ao escrever e que seja apreciado pelos internautas, tornando-os fiéis ao blog (Nardi, Schiano, Gumbrecht, \& Swartz 2004).
Para Tassigny, Oliveira Brasil, Bugarim, \& Nogueira (2012), o blog transformou-se em um forte distribuidor e intermediador de informações entre internautas e empresas. Entretanto, é necessário cuidado com o conteúdo, pois, por ser uma ferramenta aberta, pode auxiliar positivamente a tomada de decisão de seus leitores, mas também pode ser utilizado como estratégia por seus concorrentes de negócio.

Há leitoras que consideram as blogueiras como aspiração e referência para a formação de atitude, valor e comportamento e buscam se adequar por meio da compra de produtos indicados nos blogs (Mendoza, 2010). A confiança na blogueira é construída fundamentalmente com base na proximidade e na familiaridade - a blogueira é uma pessoa 'comum', poderia ser uma vizinha ou colega de trabalho - e na frequência dos contatos - as postagens são muitas vezes diárias, estabelecendo uma conversa prolongada e efetivamente presente, como se estivessem conversando com uma amiga. Os significados culturais da blogueira, portanto, mais próximos da realidade da pessoa "comum". Assim, a recomendação de um produto ou marca tem um peso semelhante ao feito por alguém do círculo social próximo desse consumidor (BrondinoPompeo, Leal \& Silva, 2017; Crescitelli \& Tagawa, 2015; Mendoza, 2010).

De acordo com Mota, Casado e Seabra (2012), ao perceberem essa influência, muitas marcas intensificaram o investimento em blogs de moda para divulgar seus produtos. A L'Oréal, por exemplo, possui desde 2009 em seu planejamento de marketing uma verba destinada a blogs, sendo uma dessas ações a organização de uma festa na casa de uma das grandes blogueiras da cidade de São Paulo, Lala Rudge, para promover a marca de cosméticos Yves Saint Laurent. Já a marca Dior apresentou sua fábrica, localizada próxima a Paris, a quatro blogueiras.

O fenômeno das blogueiras criou uma nova classe de importantes formadoras de 'opinião digital'. A proximidade e frequência com que se relacionam com nosso target [público alvo], além da forte credibilidade junto a ele, as tornaram 'incontornáveis' em nossa estratégia de comunicação", diz Alexandre Frota, superintendente da divisão de luxo da L'Oréal no Brasil, que engloba marcas como Lancôme, Ralph Lauren, Giorgio Armani, Kiehl's e Biotherm. (Mota, Casado, \& Seabra, 2012).

No Brasil, as blogueiras mais famosas (com cerca de um milhão de seguidores) ganham $\mathrm{R} \$ 18$ mil por foto que publicam no Instagram, $\mathrm{R} \$ 25$ mil para aparecer em um evento da marca e R\$ 95 mil se o trabalho envolver o comparecimento em algum evento, postagem no blog e no Instagram (Salgado, 2015). Os valores variam de acordo com a 
popularidade da blogueira, ou seja, com o número de seguidores que tem em suas redes sociais e o número de visitas que recebe em seu blog, assim como do poder de barganha que o contratante possui (Teixeira, 2014).

Outro benefício que um grande número de seguidores traz é o espaço que as blogueiras vêm ganhando na televisão, com aparição em programas de televisão (Teixeira, 2014). Além desse espaço, blogueiras vêm ganhando mordomias, como assentos privilegiados na primeira fila em desfile de grandes marcas internacionais, mostrando que a moda de luxo também está preparada para deixar a tradição e se apresentar ao público de novas maneiras (Binkley, 2009).

A construção da confiabilidade de uma blogueira é crucial para seu sucesso, uma vez que, quando sua confiabilidade é alta, os argumentos que ela apresenta são mais críveis pelo leitor e a atitude em relação aos produtos e marcas citadas é mais positiva (Chu \& Kamal, 2008).

Porém, há quem acredite que a blogueira não é tão influente a ponto de ter sucesso ao endossar uma marca, podendo prejudicar a importância que esta já chegou a construir perante seu consumidor. Primo (2009) alega que os blogs não seriam capazes de alçar seus autores à categoria de celebridades da mesma forma que o fazem a televisão e o cinema. Elas seriam celebridades restritas à blogsfera, cuja fama não extrapolaria os limites do mundo virtual. Entretanto, algumas ações verificadas nesta investigação parecem desafiar essa diferença no status defendida por Primo (2009). Quatro blogueiras de moda e beleza foram as estrelas da campanha da marca de lingerie Plié em 2015, sendo que os anúncios foram publicados em revistas de grande circulação nacional, como a Veja (SMB, 2015). Já outros quatro blogueiros desenvolveram coleções com uma marca de moda fast-fashion e estrelaram as respectivas campanhas, que incluíam também anúncios na televisão (Faria, 2017; Franklin, 2017; Glamour, 2017).

Retomando então a perspectiva de McCracken (1989) explorada na seção anterior, nota-se que o aspecto da construção cultural do significado da celebridade não pode ser ignorado. A blogueira, mesmo se estivesse ausente da mídia tradicional, é um produto do tempo e do espaço contemporâneo e seu significado foi (co)construído culturalmente com as interações próximas e frequentes com o público. Em complemento, as marcas de prestígio que passaram a utilizá-las em suas campanhas criam uma chancela de que essa barreira entre celebridade tradicional e blogueira pode ter sido vencida. A blogueira poderia ser algo novo, atual, em linha com o mundo globalizado e imediato.

\subsection{Hipóteses}

A revisão da literatura demonstrou que, com o intuito de construir um valor de marca maior, chamar mais a atenção, demonstrar personalidade, confiança, lealdade e aumentar o consumo de seus produtos, as marcas vêm se utilizando de personalidades conhecidas, tanto pela mídia, quanto pela sociedade. A literatura de marketing e consumo analisada, entretanto, ainda não explora a blogueira como sendo parte do conjunto de celebridades disponíveis para as marcas, uma vez que ela não teria atingido o mesmo status das celebridades que têm a atenção dos veículos tradicionais de mídia. Mas a nossa investigação aponta que essa mudança pode estar em curso e uma evidência seria a transposição da blogueira para além das fronteiras do mundo digital.

Assim, cabe a este estudo verificar se os fenômenos observados no mercado apresentariam uma alteração nesse status defendido até então pela literatura. Embora anteriormente poderia se argumentar que a celebridade tradicional desfrutava de um status superior ao da blogueira, os exemplos mais recentes indicam que esse status foi alterado, especialmente se se considera o significado cultural de proximidade, familiaridade e imediatismo que uma personalidade digital possui. Dessa forma, supõe-se que:

H1: A atitude em relação à marca é maior quando esta é endossada por uma blogueira.

Voltando para o modelo da credibilidade da fonte, os significados de proximidade e familiaridade podem ter efeitos na credibilidade da blogueira. Assim, presume-se:

H2: As blogueiras possuem credibilidade maior como endossantes de marca.

\section{PERCURSO METODOLÓGICO}

Para testar as hipóteses, foi feito um experimento. A variável independente é o tipo de endosso: se feito por celebridade ou por blogueira. Para isso, foi criado um anúncio de um produto, no qual o entrevistado escolhe uma celebridade ou blogueira de sua preferência como endossante, a fim de saber qual possui impacto mais positivo na atitude em relação à marca, que é a variável dependente deste estudo.

\subsection{Instrumentos De Coleta}

Para o processo de mensuração das variáveis e das hipóteses, foram pesquisadas 
diversas escalas que tivessem relação com os objetivos, com a variável independente e com as hipóteses do estudo. Dentre todas as escalas pesquisadas, foram selecionadas duas que respondem ao objetivo principal e às hipóteses.

A primeira é a escala source credibility perception, de Ohanian (1990), que é composta por atributos que medem a credibilidade da fonte em vários aspectos, considerando as qualidades relacionadas à aparência e à profissão. A escala está dividida em três dimensões: atratividade, confiabilidade e experiência, sendo que cada uma é composta por cinco itens de diferencial semântico.
A outra escala usada foi de atitude em relação à marca, adaptada das escalas usadas por Graeff (1996) e por MacKenzie e Lutz (1989). Tratase de uma escala unidimensional com quatro itens de diferencial semântico.

Antes de seus empregos na coleta, ambas as escalas passaram por uma tradução reversa (Malhotra, 2006). Três itens da dimensão de confiabilidade da escala de credibilidade receberam a mesma tradução em três etapas de retrotradução. Dessa forma, foram reduzidos a apenas um item. A Figura 1 mostra os itens das escalas nas versões originais e o resultado da tradução.

\begin{tabular}{|c|c|c|}
\hline Escalas & Original & Tradução Final \\
\hline \multirow{18}{*}{$\begin{array}{c}\text { Source credibility } \\
\text { perception } \\
\text { (OHANIAN, 1990) }\end{array}$} & Attractiveness & Atratividade \\
\hline & Attractive-Unattractive & Atrativo - não atrativo \\
\hline & Classy-Not classy & Com classe - sem Classe \\
\hline & Beautiful-Ugly & Bonito - feio \\
\hline & Elegant-Plain & Elegante - sem graça \\
\hline & Sexy-Not sexy & Sexy - não sexy \\
\hline & Trustworthiness & Confiabilidade \\
\hline & Honest-Dishonest & Honesto - desonesto \\
\hline & Sincere-Insincere & Sincero - não sincero \\
\hline & Reliable-Unreliable & \multirow{3}{*}{ Confiável - não confiável } \\
\hline & Dependable-Undependable & \\
\hline & Trustworthy-Untrustworthy & \\
\hline & Expertise & Experiência \\
\hline & Expert-Not an expert & Especialista - não especialista \\
\hline & Experienced-Inexperienced & Experiente - inexperiente \\
\hline & Knowledgeable-Unknowledgeable & Conhecedor - sem conhecimento \\
\hline & Qualified-Unqualified & Qualificado - não qualificado \\
\hline & Skilled-Unskilled & Talentoso-Não Talentoso \\
\hline \multirow{4}{*}{$\begin{array}{c}\text { Atitude em relação à } \\
\text { marca (GRAEFF, 1996; } \\
\text { MACKENZIE; LUTZ, } \\
\text { 1989) }\end{array}$} & Favorable - unfavorable & Favorável - não favorável \\
\hline & Good - bad & Bom - ruim \\
\hline & Like - dislike & Gosta - não gosta \\
\hline & Pleasant - unpleasant & Agradável - desagradável \\
\hline
\end{tabular}

Figura 1 - Itens das escalas da covariável e da variável dependente.

Fonte: Adaptado e traduzido de Graeff (1996), Mackenzie e Lutz (1989) e Ohanian (1990).

Quanto ao estímulo, foi apresentado o anúncio de um produto sendo endossado por uma blogueira ou celebridade. Entretanto, no lugar da foto da suposta blogueira ou celebridada havia apenas um esboço de silhueta feminina. A escolha dessa endorser foi do entrevistado, que escolheu uma celebridade ou blogueira de sua preferência e solicitou-se que a mantivesse em mente para responder o questionário. Dessa forma, garantiu-se que a escolha fosse sempre de alguém que agradasse o respondente, eliminando-se o efeito que a escolha de celebridade ou blogueira específica pudesse causar.

\subsection{Amostragem}

A amostragem deste estudo foi feita por conveniência, com uma seleção não probabilística, dentro dos círculos sociais das autoras, com homens e mulheres que têm interesse e contato com moda, celebridades e blogueiras.

Não houve restrição de idade ou sexo, uma vez que qualquer indivíduo pode ser suscetível à influência de endossantes em anúncios. 


\subsection{Procedimento da Coleta}

A coleta foi realizada outubro de 2015 por meio de uma plataforma online de pesquisa (http://pt.surveymonkey.net). Os respondentes foram direcionados às duas situações de estímulo a partir de seus meses de nascimento. Para as pessoas que responderiam sobre blogueiras, foi feita uma pergunta para filtragem: se ela lê, ao menos uma vez por semana, algum blog de moda ou beleza, ou segue alguma blogueira no Instagram, Facebook, Twitter, Snapshat ou Periscope. Somente as pessoas que respondessem positivamente a essa pergunta continuaram com o preenchimento.

$\mathrm{Na}$ sequência, foi apresentado um anúncio fictício (Figura 2), revelando uma linha nova de produtos para cabelo, de uma marca conhecida, e com uma sombra feminina, representando a garotapropaganda do produto.

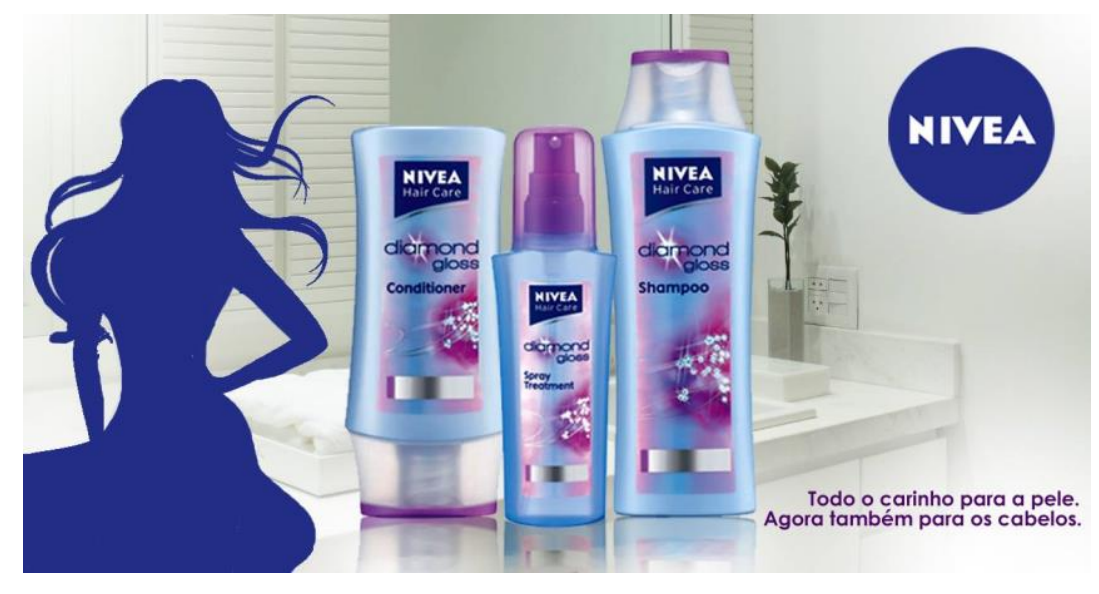

Figura 2 - Anúncio fictício utilizado na coleta Fonte: Elaboração própria, 2015.

Para escolher a marca, levou-se em consideração três critérios. Primeiramente, seria necessário que fosse uma marca de produtos de moda ou beleza, uma vez que são esses setores que apresentaram, durante a fase de levantamento bibliográfico e documental, os casos mais relevantes de atenção das blogueiras. Também seria importante que a marca em questão não tivesse feito até o momento do estudo ações de endosso envolvendo nem celebridades e nem blogueiras, para que lembranças de ações anteriores não influenciassem a avaliação do anúncio do estímulo. Além disso, seria ideal que a marca usada não estivesse, no momento anterior próximo à e durante a coleta, realizando nenhuma campanha publicitária de extensa cobertura, também com o objetivo de que a lembrança de anúncios efetivamente publicados pela marca gerasse alguma contaminação na avaliação do anúncio do estímulo. A marca Nivea preencheu todos esses requisitos.

Para as pessoas que responderiam sobre celebridades, foi pedido que, no lugar da sombra feminina, estas pensassem que a garota-propaganda do anúncio fosse uma atriz, cantora, modelo ou apresentadora, cuja beleza e estilo de vida fossem admirados. Já para as pessoas que responderiam sobre blogueiras, foi passada basicamente a mesma instrução - a única diferença é que esses respondentes deveriam pensar numa blogueira.
Dessa forma, garantiu-se que a escolha fosse sempre de alguém que agradasse o respondente, eliminandose o efeito que a escolha de celebridade ou blogueira específica pudesse causar. O respondente registrou o nome da pessoa em que ele pensou, e essa resposta foi utilizada para verificação.

Na sequência, os participantes responderam às questões de atitude em relação à marca e de credibilidade da fonte. As perguntas finais caracterizaram a amostra em relação a renda, cidade de moradia, atuação, idade e sexo. O questionário foi pré-testado e realizados pequenos ajustes antes da coleta.

\section{ANÁLISE DOS DADOS}

Obteve-se um total de 160 respostas, das quais 32 foram excluídas por apresentarem respostas incompletas na escala da variável dependente ou tempo incompatível com o preenchimento do questionário, restando 128 para serem analisadas. Destas 128 respostas, quatro não responderam às cinco questões finais referentes ao perfil - renda, cidade, onde mora, atuação, idade e sexo - e não constituirão a amostra para a análise de perfil, embora tenham permanecido na base para o teste das hipóteses. 
A faixa etária dos respondentes variou entre 15 e 58 anos, sendo que a média de idade foi de 27 anos. $84,7 \%$ desse público é do sexo feminino, enquanto $15,3 \%$ do sexo masculino. $86,3 \%$ da amostra reside no Estado de São Paulo, 8,9\% reside em outros Estados brasileiros, e o restante em outros países. Quanto à ocupação, 33,1\% estuda e trabalha, os mesmos $33,1 \%$ só trabalha, $25,0 \%$ só estuda e o restante não trabalha e nem estuda.

\subsection{Confiabilidade e Estrutura das Escalas}

Para analisar a confiabilidade das escalas, foi utilizado o teste de Alfa de Cronbach $\left(\propto_{\text {atitude marca }}\right.$ $=0,88 ; \propto_{\text {credibilidade fonte }}=0,92$ ). No caso da escala de credibilidade, composta por treze itens separados em três dimensões, também foi feito o teste para cada dimensão, que ficou em 0,83 e 0,90.

As escalas foram submetidas à análise de correlação de seus itens e à análise fatorial exploratória para verificar a estrutura. Os quatro itens da escala de atitude em relação à marca apresentaram índices significativos e superiores a 0,58 . Já na escala de credibilidade da fonte, alguns itens apresentaram correlações em torno de 0,25, apontando para uma estrutura multidimensional.

$\mathrm{O}$ teste de Bartlett e a Medida de Adequação de Amostra de Kaiser (KMO) demonstraram que a amostra poderia ser submetida a uma análise fatorial. Tanto a escala de atitude em relação à marca (atitude em relação à marca Bartlett $\chi^{2}(6)=280,9129, p<0,001 ; \mathrm{KMO}=0,83$; e credibilidade da fonte Bartlett $\chi^{2}(78)=1124,966, p$ $<0,001 ; \mathrm{KMO}=0,92$ ).

Os itens da escala de atitude em relação à marca apresentaram comunalidades superiores a 0,66 e apenas um componente foi capaz de explicar $74,7 \%$ da variância. As cargas na matriz de componentes foram superiores a 0,81. Com isso, confirmou-se sua dimensão única, conforme previsto na literatura revista.

$\mathrm{Na}$ escala de credibilidade da fonte as comunalidades extraídas foram superiores a 0,5. Obteve-se dois fatores com autovalor acima de 1 , mas sabendo que a versão original desta escala possuía três dimensões, decidiu-se pela extração de três componentes. Os três componentes são capazes de juntos, explicarem $74,4 \%$ da variância.

Optou-se pelo método de rotação Oblimin, uma vez que ele permite que os componentes se correlacionem (Field, 2009), o que está em linha com a teoria sobre credibilidade da fonte. Todos os itens, em seus respectivos componentes, apresentaram cargas fatoriais superiores a 0,5. Notou-se que uma das dimensões reúne características mais ligadas à qualificação do trabalho da personalidade (especialista, experiente, conhecedora, qualificada), outra agrupa características mais ligadas às características individuais e de aparência (sexy, bonita, elegante, com classe, talentosa) e a terceira aspectos de confiabilidade (honesta, sincera, confiável).

A versão em português se assemelha bastante à versão original da escala. A dimensão atratividade da escala original coincide com umas das dimensões aqui extraída, com exceção de um item: talentosa/ não talentosa, que não versão original pertencia à dimensão experiência. Com exceção desse item, os itens na versão original estavam divididos da mesma maneira.

Com a estrutura e a confiabilidade das escalas devidamente analisadas, os itens de cada uma delas foram reduzidos à média. Os dados foram submetidos a um estudo de distribuição de frequência, assimetria e curtose. Concluiu-se que os dados da coleta não violam os princípios da normalidade e, portanto, serão submetidos à análise de covariância.

\subsection{Testes das Hipóteses}

Concluídas as análises de estrutura das escalas, e satisfeitas as condições de normalidade dos dados, iniciou-se o processo de testes das hipóteses, utilizando a análise de covariância (ANCOVA). O tipo de personalidade endossante blogueira ou celebridade - é a variável independente, a atitude em relação à marca a variável dependente $\mathrm{e}$ a credibilidade da endossante a covariável.

Antes de realizar a ANCOVA, foram feitos análise de correlação e teste-t para verificar se as premissas básicas dessa análise poderiam ser satisfeitas. Para que seja adequado realizar a ANCOVA, a variável dependente e a covariável devem ter boa correlação e a média da covariável não pode ser significativamente diferente nos dois grupos da variável manipulada (Field, 2009). Foi encontrada correlação significativa entre variável dependente e covariável $(r=0,61, p<0,01)$ e o teste-t apontou que não há diferença da média da covariável nos dois grupos de tratamento $\left(\mathbf{M}_{\text {celebridade }}\right.$ $\left.=6,13, \mathrm{M}_{\text {blogueira }}=5,85, \mathrm{t}(78)=1,709, p>0,05\right)$. Com esse teste, já fica evidente que não há suporte para H2. Dessa forma, podemos afirmar que não há diferença significativa na credibilidade de blogueiras e celebridades.

A análise de correlação mostrou também que não foi encontrada correlação entre a variável dependente e a independente $(r=-0,079, p<0,01)$. Portanto, antecipadamente já se pode esperar que não haja relação de causalidade entre elas na ANCOVA.

O teste de efeitos entre os assuntos mostra que não foi encontrado efeito da variação da personalidade endossante - se blogueira ou celebridade - na atitude em relação à marca, não 
havendo, portanto, sustentação para $\mathrm{H} 1\left(\mathrm{M}_{\text {celebridade }}=\right.$ $\left.5,73, \mathrm{M}_{\text {blogueira }}=5,52, \mathrm{~F}(1,126)=0,039, p>0,05\right)$.

Com isso, pode-se dizer que não foram encontradas evidências de que o endosso feito por blogueira ou celebridade teriam efeitos distintos na atitude em relação à marca, e ambas desfrutariam atualmente de percepção de credibilidade equivalente.

\section{CONCLUSÕES}

A revisão da literatura e a pesquisa documental mostrou que, para transmitir significados e valores a seus potenciais consumidores, as organizações se utilizam do endosso de marca.

O endosso feito por celebridades é uma estratégia já muito utilizada pelas empresas, enquanto as blogueiras constituem um fenômeno recente que criou uma nova classe de importantes líderes de opinião digital. Apesar de relativamente recente, as blogueiras influenciam um grande número de pessoas, apresentando um alto número de seguidores. Com essas duas líderes de opinião e possibilidades de atuarem como endossantes para uma marca, surgiu a dúvida de qual traria mais atitude positiva para a marca.

A literatura investigada não apresentava modelos causais comparando os efeitos de celebridades e blogueiras e havia visões conflitantes: de um lado, a visão de que blogueira e celebridade estariam em patamares distintos em seu poder e extensão de influência na atitude em relação à marca que anunciavam (Primo, 2009); por outro lado, a perspectiva de uma mudança nessa situação estaria em curso e que ambas poderiam se equiparar (Keel \& Nataraajan, 2012; Zanette, 2015), uma vez que, além da credibilidade da fonte, o significado cultural construído é fator relevante no sucesso do endosso (McCracken, 1989).

Combinando as informações do referencial teórico e da pesquisa documental, levantou-se a hipótese de que, atualmente, blogueiras estariam desfrutando de credibilidade superior como endorsers de marca, sendo essa melhora no conceito de credibilidade da blogueira devida a sua maior proximidade e familiaridade com os consumidores.

A análise dos dados coletados indicou que o fato de a endossante ser uma celebridade ou blogueira é indiferente para a atitude em relação à marca e que ambas possuem credibilidade equivalente. Assim, os dados não sustentam que a blogueira tenha adquirido status superior, mas sim encontra-se no mesmo patamar das celebridades tradicionais. Isso fica mais evidente quando, ao se analisar alguns dos questionários respondidos que, quando se pedia uma celebridade, alguns respondentes apontaram o nome de uma blogueira.

Além disso, foi pedido para que o entrevistado escolhesse a pessoa - celebridade ou blogueira - que estrelaria a campanha usada como estímulo, o que pode afetar positivamente o desempenho do anúncio. Dessa forma, nota-se que é mais importante que a empresa seja eficiente em detectar quem é a personalidade mais admirada pelo público-alvo em função dos significados culturais que foram por e para ela construídos, já que provavelmente esse é um dos fatores importantes na atitude positiva em relação à marca, do que decidir se ela deve pertencer à classe das celebridades tradicionais ou das blogueiras.

Outro ponto observado durante a análise de dados foi em relação à escala de credibilidade da fonte, que apresentou apenas ligeiras alterações em relação à escala original e alcançou bom índice de confiabilidade. Assim, este estudo contribui também para futuras mensurações no tema, oferecendo uma escala adicional para estudos seguintes relativos à credibilidade da fonte.

Como limitações deste estudo, cabe ressaltar que foi testado apenas um tipo de categoria de produto, de apenas uma marca, e, derivada dessa escolha de categoria e marca, apenas um perfil de blogueira e de celebridade. Além disso, optou-se por uma marca conhecida. Marcas desconhecidas poderiam gerar resultados diferentes e uma corroboração ou refutação dessa premissa em estudos futuros traria grande benefício ao conhecimento no tema. Em outras categorias de produto e perfil de personalidade escolhida como endossante - atletas, por exemplo - os resultados podem ser diferentes. Com o crescente interesse das empresas nos blogueiros para estrelar suas campanhas, e sabendo que vivemos numa era de mudanças velozes no cenário digital, essa se torna uma investigação cuja continuidade é de alta relevância.

Estudos futuros no tema poderiam investigar, em uma situação na qual o público-alvo é mais heterogêneo, e, portanto, mais difícil escolher uma personalidade que agradasse de forma homogênea, se seria melhor o endosso de um(a) blogueira(o) ou uma celebridade. Ainda, poderia ser comparado o uso dos dois tipos de endossantes com um anúncio sem nenhum endossante, o que contribuiria ainda mais para o conhecimento do tema e para as decisões dos gestores. 


\section{REFERÊNCIAS}

Aquino, M. C. (2009). Os blogs na web 2.0: Representação e recuperação coletivas de informação. In A. Amaral, R. Recuero e S. P. Montardo (Orgs.), Blogs. com: estudos sobre blogs e Comunicação (pp. 237-256). São Paulo: Momento Editorial.

Binkley, C. (2009, Outubro 2). From the runway to your laptop: in Milan, European labels such as Dolce \& Gabbana embrace the digital age. The Wall Street Journal, New York City, On Style. Recuperado em Outubro 20, 2014, de http://www.wsj.com/articles/SB1000142405274870 4471504574445222739373290.

Brockington, D. (2015). Towards an international understanding of the power of celebrity persuasions: a review and a research agenda. Celebrity Studies, 6(4), 486-504. https://doi.org/10.1080/19392397.2015.1087214

Brondino-Pompeo, Karin L., Leal, Marcela B., \& Silva, Diego dos S. (2017). Uma breve morfologia da influência digital. Manuscrito não publicado. ESPM, Núcleo de Pesquisa em Marketing, São Paulo, SP.

Byrne, A., Whitehead, M., \& Breen, S. (2003). The naked truth of celebrity endorsement. British Food Journal, 105(4/5), 288-296.

https://doi.org/10.1108/00070700310477086

Choi, S. M., \& Rifon, N. J. (2012). It is a match: The impact of congruence between celebrity image and consumer ideal self on endorsement effectiveness. Psychology \& Marketing, 29(9), 639650. https://doi.org/10.1002/mar.20550

Chu, S. \& Kamal, S. (2008). The effect of perceived blogger credibility and argument quality on message elaboration and brand attitudes: An exploratory study. Journal of Interactive Advertising, 8(2), 26-37.

https://doi.org/10.1080/15252019.2008.10722140

Crescitelli, E., \& Tagawa, Y. (2015). A influência dos blogs na decisão de compra: um estudo exploratório no segmento de beleza. Comunicação \& Sociedade, 37(2), 49-79. http://dx.doi.org/10.15603/2175-7755/cs.v37n2p4979

Dal Bó, G., Milan, G. S., \& De Toni, D. (2012). O endosso por celebridade e a gestão da imagem da marca: Evidências empíricas a partir do estudo da marca Ipanema Gisele Bündchen. REAd. Revista Eletrônica de Administração (Porto Alegre), 18(3),
681-717. http://dx.doi.org/10.1590/S141323112012000300005

Ego (2015, Março 4). Sabrina Sato explica que vídeo íntimo foi feito para campanha. Recuperado em Abril 13, 2015, de

http://ego.globo.com/famosos/noticia/2015/03/sabri na-sato-explica-que-video-intimo-foi-feito-paracampanha.html.

Escalas, J. E. \& Bettman, J. R. (2005). Selfconstrual, reference groups, and brand meaning. Journal of Consumer Research, 32(3), 378-389. https://doi.org/10.1086/497549

Faria, L. (2017, Fevereiro 26). Camila Coutinho lança coleção em parceria com Riachuelo. Veja São Paulo, Editora Abril, São Paulo. Recuperado em Dezembro 12, 2017, de https://vejasp.abril.com.br/blog/liquidacaocia/camila-coutinho-lanca-colecao-em-parceriacom-riachuelo/

Field, A. (2009). Discovering statistics using SPSS: Introducing statistical method. London: Sage.

Forbes Brasil (2015, Fevereiro). 30 abaixo de 30. Listas, Forbes Brasil, São Paulo. Recuperado em Janeiro 03, 2018, de http://www.forbes.com.br/listas/

Franklin, L. (2017, Maio 31). Riachuelo e HOPE têm novas coleções de lingeries. Veja São Paulo, Editora Abril, São Paulo. Recuperado em Novembro 03, 2017, de https://vejasp.abril.com.br/blog/liquidacaocia/riachuelo-hope-lingeries-nova-colecao/

Freire, R., Behling, H. P., \& Reinert, J. (2010, Maio). Endosso de celebridades: Uma análise baseada na complementaridade de modelos teóricos. Artigo apresentado no XI Congresso de Ciências da Comunicação na Região Sul, Novo Hamburgo, RS. Intercom - Sociedade Brasileira de Estudos Interdisciplinares da Comunicação.

Recuperado de http://www.intercom.org.br/papers/regionais/sul201 0/resumos/R20-0399-1.pdf

Garotas Estúpidas (2017). Sobre. Garotas Estúpidas. Recuperado em Maio 11, 2017, de http://www.garotasestupidas.com/sobre-camilacoutinho/

Glamour (2017, Março 31). Camila Coelho e Kadu Dantas assinam coleção para a Riachuelo. Fashion News. Recuperado de http://revistaglamour.globo.com/Moda/Fashion- 
news/noticia/2017/03/camila-coelho-e-kadu-dantasassinam-colecao-para-riachuelo.html

Goldsmith, R. E. (2000). Characteristics of the heavy user of fashionable clothing. Journal of Marketing Theory and Practice, 8(4), 21-28. https://doi.org/10.1080/10696679.2000.11501877

Graeff, T. R. (1996). Using promotional messages to manage the effects of brand and self-image on brand evaluations. Journal of Consumer Marketing, 13(3), 4-18.

https://doi.org/10.1108/07363769610118921

Hovland, C. I., \& Weiss, W. (1951). The influence of source credibility on communication effectiveness. Public Opinion Quarterly, 15(4), 635-650. https://doi.org/10.1086/266350

Hung, K. (2014). Why celebrity sells: A dual entertainment path model of brand endorsement. Journal of Advertising, 43(2), 155166.

https://doi.org/10.1080/00913367.2013.838720

Jin, S. A. A., \& Phua, J. (2014). Following celebrities' tweets about brands: The impact of twitter-based electronic word-of-mouth on consumers' source credibility perception, buying intention, and social identification with celebrities. Journal of Advertising, 43(2), 181-195. https://doi.org/10.1080/00913367.2013.827606

Kaplan, A. M., \& Haenlein, M. (2010). Users of the World, Unite! The Challenges and Opportunities of Social Media. Business Horizons, 53(1), 59-68. https://doi.org/10.1016/j.bushor.2009.09.003

Keel, A., \& Nataraajan, R. (2012). Celebrity endorsements and beyond: New avenues for celebrity branding. Psychology \& Marketing, 29(9), 690-703. https://doi.org/10.1002/mar.20555

Keller, K. L. (2003). Brand synthesis: The multidimensionality of brand knowledge. Journal of Consumer Research, 29(4), 595-600. https://doi.org/10.1086/346254

Keller, K. L., \& Lehmann, D. R. (2006). Brands and branding: Research findings and future priorities. Marketing Science, 25(6), 740-759. https://doi.org/10.1287/mksc.1050.0153

McCracken, G. (1989). Who is the celebrity endorser? Cultural foundations of the endorsement process. Journal of Consumer Research, 16(3), 310-321. https://doi.org/10.1086/209217
MacKenzie, S. B., \& Lutz, R. J. (1989). An empirical examination of the structural antecedents of attitude toward the ad in an advertising pretesting context. The Journal of Marketing, 53(2), 48-65.

Malhotra, N. K. (2001). Pesquisa de marketing: Uma orientação aplicada (3. ed). Porto Alegre: Bookman.

Mendoza, M. (2010). I Blog. You Buy. How bloggers are creating a new generation of product endorsers. Journal of Digital Research \& Publishing, 7, 114-122. Recuperado de https://ses.library.usyd.edu.au/bitstream/2123/8134/ 1/DRPJournal_7pm_S1_2010.pdf\#page=114

Mota, C. V., Casado, L., \& Seabra, L. (2013, Janeiro 29). Blog de moda é novo canal de venda. Valor Econômico. Recuperado de http://www.valor.com.br/empresas/2507028/blogde-moda-e-novo-canal-de-venda

Nardi, B. A., Schiano, D. J., Gumbrecht, M., \& Swartz, L. (2004). Why we blog. Communications of the ACM, 47(12), 41-46.

Ohanian, R. (1990). Construction and validation of a scale to measure celebrity endorsers' perceived expertise, trustworthiness, and attractiveness. Journal of Advertising, 19(3), 39-52.

Ohanian, R. (1991). The impact of celebrity spokespersons' perceived image on consumers' intention to purchase. Journal of Advertising Research, 31(1), 46-54.

Primo, A. (2009). Existem celebridades da e na blogosfera? Reputação e renome em blogs. Líbero, 12(24), 107-116.

Rocha, P. J. (2008). Blogs: sentimentos em rede compartilhados na pós-modernidade. Revista Famecos, 10(22), 73-82.

Rojek, C. (2008). Celebridade. Rio de Janeiro: Rocco.

Salgado, M. (2015, Fev). \#digitalglam: como virar uma estrela das mídias sociais. Glamour, Editora Globo, 35.

Schittine, D. (2004). Blog: Comunicação e escrita intima na internet. Rio de Janeiro: Editora Record.

Silva, L. B. \& Baptista, L. (2013). Kate e Kim: Os arquétipos e a formação da celebridade. Congresso de Estudantes de Pós-Graduação em Comunicação, VI. Rio de Janeiro: CONECO. Disponível em http://www.coneco.uff.br/content/anais_. 
Silva, L., Lopes, E., Freire, O., \& Silva, D. (2012). O efeito da marca na avaliação de propagandas endossadas por celebridades: Um estudo experimental. Encontro Anual da Associação Brasileira dos Programas de Pós-Graduação em Administração, 36. Rio de Janeiro: Enanpad. Disponível em http://www.anpad.org.br/ anpad/eventos.php?cod_ evento $=1 \&$ cod_edicao_subsecao $=848 \&$ cod_evento _edicao $=63 \&$ cod_edicao_trabalho $=15202$.

SMB (2015). Plié Lança Campanha Com Influenciadoras Digitais. Salão da Moda Brasil, Notícias. Disponível em http://www.salaomodabrasil.com.br/plie-lancacampanha-com-influenciadoras-digitais.html

Taschner, G. (2010). Comunicação, sociedade e imaginários do consumo. Comunicação Mídia e Consumo, 7(20), 37-57.
Tassigny, M. M., de Oliveira Brasil, M. V., Bugarim, M. C., \& Nogueira, F. L. B. M. (2012). Blog: ferramenta estratégica de comunicação organizacional. Revista de Administração da UFSM, 5(2), 262-276.

Teixeira, M. (2014, Jul 07). Blogueiros profissionais ganham muito dinheiro com posts na internet. Brasil Econômico, São Paulo. Disponível em

http://economia.ig.com.br/financas/seunegocio/2 014-11-07/blogueiros-profissionais-ganham-muitodinheiro-com-posts-na-internet.html

Watts, D. J., \& Dodds, P. S. (2007). Influentials, networks, and public opinion formation. Journal of Consumer Research, 34(4), 441-458.

Zanette, M. C. (2015). Influência digital: O papel dos novos influentes no consumo. Curitiba: Appris. 